\title{
Pesticide intoxications in the Centre of Portugal: three years analysis
}

\author{
Helena Teixeira ${ }^{a, b, *}$, Paula Proença ${ }^{a}$, Margarida Alvarenga ${ }^{a}$, Margarida Oliveira ${ }^{a}$, \\ Estela P. Marques $^{\mathrm{a}, \mathrm{b}}$, Duarte Nuno Vieira ${ }^{\mathrm{a}, \mathrm{b}}$ \\ ${ }^{a}$ Delegation of Coimbra, National Institute of Legal Medicine, Coimbra, Portugal \\ ${ }^{\mathrm{b}}$ Faculty of Medicine, University of Coimbra, Coimbra, Portugal
}

Received 20 November 2003; accepted 13 February 2004

Available online 25 May 2004

\begin{abstract}
Pesticides are used in most countries around the world to protect agricultural and horticultural crops against damage. Poisoning by these toxicant agents occurs as a result of misuse or accidental exposure, and also by oral ingestion (voluntary or not).

In Portugal, pesticide intoxications are still a cause of death, found in a considerable number of cases.

The authors retrospectively examined the cases of pesticide poisoning in the Centre of Portugal, from autopsies performed in the Forensic Pathology Service of Coimbra's Delegation of the National Institute of Legal Medicine (NILM) and from other autopsies carried out in the Centre of Portugal, as well as some samples taken in hospitals in cases of suspected intoxication.

In this study, the positive cases have been especially studied, in order to identify the pesticide used, as well as the etiology. The frequency of intoxications and its distribution by sex and age were also analyzed.

Between January 2000 and December 2002, the Forensic Toxicology Laboratory received 639 pesticide analysis requests. In 2000, in a total of 149 analysis requests, 30 cases were positive, $63.3 \%$ from male individuals and $36.7 \%$ from female. In 2001, the analysis requests increased to 240 as well as the positive cases (43), $74.4 \%$ from male individuals and $25.6 \%$ from female and in 2002 , the total cases analyzed also increased to 250 , with 38 positive ( $73.6 \%$ from male individuals and $26.4 \%$ from female).

Among the pesticides, organophosphorus insecticides still constitute the most important class detected in forensic intoxications, representing $63 \%$ of the total positive cases, followed by herbicides, with $33 \%$ of the positive results. Quinalphos is the most important organophosphorus insecticide, present in 32 of the 111 positive cases, followed by the herbicide paraquat, detected in 31 cases.

The study emphasizes the increasing number of pesticide analyses, particularly relevant for the organophosphorus compounds and herbicides. Intoxication suspicion, accidental or voluntary, seems to be the most common cause of the incidents, for which analyses are requested, but it is also evident that the putative cause is unknown in a large number of cases. Therefore, more stringent legislation and enforcement regarding the sale and distribution of these toxic substances are needed.
\end{abstract}

(C) 2004 Elsevier Ireland Ltd. All rights reserved.

Keywords: Forensic intoxication; Pesticides; Retrospective study

\section{Introduction}

Pesticides are used in most countries around the world to protect agricultural and horticultural crops against damage.

\footnotetext{
* Corresponding author. Tel.: +351-239-854230; fax: +351-239-836470.

E-mail address: helenateixeira@dcinml.mj.pt (H. Teixeira).
}

They are also used at home and at work to insure a pest-free environment. Most poisonings by pesticides occur as a result of misuse or accidental exposure. At home, poisoning usually occurs by oral ingestion (voluntary or not); occupational users most frequently encounter dermal exposure or inhalation [1,2].

The same classes of pesticides are used all over the world, but conditions of use vary widely, and public perceptions of 
risk vary even more widely. Pesticide residues in commercially traded foodstuffs are subject to international standards and are closely monitored. Hence, risks to consumers from such foods are negligible. The major hazards are poisonings associated with high acute/chronic exposures due to occasional pesticide misuse by operators. In addition, pesticides provide a convenient means of attempting suicide in agricultural areas [3]. Overall, pesticides account for a small, but increasing number of human intoxication cases, which are not always well diagnosed or documented. Furthermore, the acute lethal doses of many pesticides in humans remain to be established [4].

Levine and Doull [5] reported that mathematical models have projected increasing numbers of pesticide poisoning throughout the world, rising from 500,000 cases/year in 1972 to $25,000,000$ cases/year in a 1990 estimate. They also stated that among 148 outbreaks (excluding Bhopal and three probable epidemics of pesticide-related suicide) reported between 1951 and 1990, the known number of cases were 24,731 with 1065 deaths (4.3\% case fatality).

In Portugal, pesticide intoxications investigated in the National Institute of Legal Medicine (NILM) are still found to be a significant cause of death. Therefore, the aim of this work was to analyze the intoxication cases due to pesticides in the Centre of Portugal, from autopsies performed in the Forensic Pathology Service of Coimbra's Delegation of the NILM and from other autopsies carried out in the Centre of Portugal, as well as some samples taken in hospitals in cases of suspected intoxication, and to emphasize the need to control the problem on a collaborative basis by all concerned.

\section{Material studied}

As data material of the present study, 639 pesticide analysis requests, from January 2000 to December 2002 were reviewed with reference to findings related to pesticides.

Pesticide analyses were performed in the Forensic Toxicology Laboratory of the Coimbra's Delegation of the NILM of Portugal, using different biological samples when appropriate (blood, stomach, liver, lung, kidney) by chromatographic methods, gas chromatography with flame-photometric detection (GC-FPD) [6], and gas chromatography-mass spectrometry (GC-MS) [7,8], and using molecular absorption spectroscopy with a photodiode array detector for paraquat analysis, measuring optic density at a $605 \mathrm{~nm}$ wavelength [9].

Assessment of the examination protocols was conducted by means of a tabular database according to the following criteria: year, age, sex, cause of death and/or cause of poisoning information, and active agent or substance classification.

On account of the structure and purpose of the material under study as well as that of the results obtained, only the positive cases have been especially studied.

\section{Results}

\subsection{Number of cases}

The total number of requests for human pesticide toxicological analyses made to the Coimbra's Delegation of the Portuguese NILM between January 2000 and December 2002 was 639, 149 in 2000, 240 in 2001, and 250 in 2002 (Table 1). In 2000, 30 cases (20.1\% of the 149 analyses requested) were confirmed intoxications, 19 (63.3\%) from male individuals and 11 (36.7\%) from female. In 2001, from the 240 analyses requested, $43(18.0 \%)$ were positive cases, $32(74.4 \%)$ from male individuals and $11(25.6 \%)$ from female. In 2002, $15.2 \%$ (38) of the 250 cases analyzed were confirmed intoxications, $28(73.6 \%)$ from male individuals and $10(26.4 \%)$ from female (Table 1$)$.

\subsection{Requests}

From the total number of pesticide analyses requested (639) between January 2000 and December 2002, 22\% were asked by hospitals, $38 \%$ by the Forensic Pathology Service of the Delegation of Coimbra of the NILM of Portugal, 27\% were obtained from Courts belonging to the Centre of Portugal, and $13 \%$ were from others, including personal requests (Fig. 1A).

From the toxicological questionnaire utilized to request a pesticide analysis, we have obtained important indications about the putative cause of intoxication of the case. Seventeen percent of the total requests had indication of intoxication suspicion, $13 \%$ of suicide, $1 \%$ of homicide, $1 \%$ of accident, and $2 \%$ of non-defined causes (Fig. 1B). However, $66 \%$ of the requests have no information at all about the putative cause of the incident.

\subsection{Sex and age distribution}

Males represented about $71.2 \%$ of the positive cases for pesticides (Table 1). Age and sex distribution of the total positive cases is presented in Fig. 2. The age distribution was similar in males and females, except in the age group of 41-50 years, which had the highest number of pesticide

Table 1

Number of pesticide analysis requests between January 2000 and December 2002 and the corresponding number of confirmed pesticide cases

\begin{tabular}{lllll}
\hline Year & $\begin{array}{l}\text { Analysis } \\
\text { requests }\end{array}$ & \multicolumn{2}{l}{ Positive cases } \\
\cline { 3 - 5 } & & $\begin{array}{l}\text { Total, } \\
n(\%)\end{array}$ & $\begin{array}{l}\text { Male, } \\
n(\%)\end{array}$ & $\begin{array}{l}\text { Female, } \\
n(\%)\end{array}$ \\
\hline 2000 & 149 & $30(20.1)$ & $19(63.3)$ & $11(36.7)$ \\
2001 & 240 & $43(18.0)$ & $32(74.4)$ & $11(25.6)$ \\
2002 & 250 & $38(15.2)$ & $28(73.6)$ & $10(26.4)$ \\
Total & 639 & $111(17.4)$ & $79(71.2)$ & $32(28.8)$ \\
\hline
\end{tabular}




\section{A - Origin of requests}

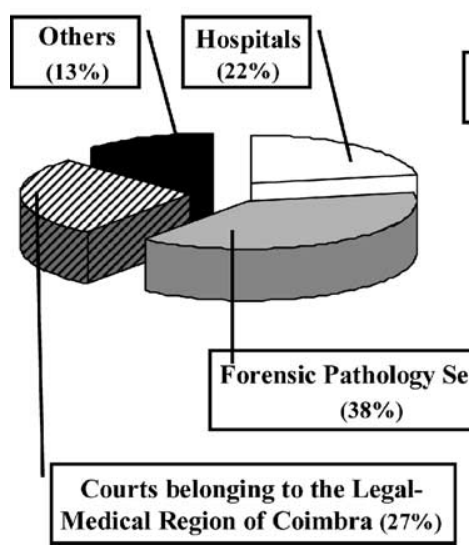

B - Putative cause indicated in the request form

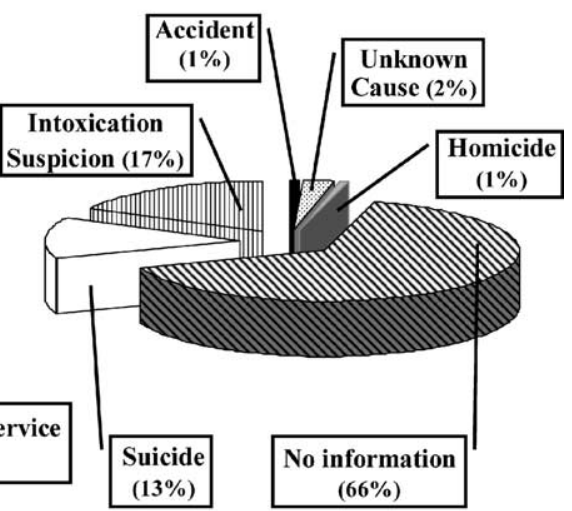

Fig. 1. Origin of request and putative cause indicated in the request forms of pesticide intoxication cases between January 2000 and December 2002.

intoxications. It is also interesting to note a higher value in the age group of 61-70 years and after 71 years.

\subsection{Detected pesticides}

The total number of pesticides detected by the toxicological analysis is presented in Table 2, as well as its distribution by sex.

The most frequently encountered pesticides were quinalphos and paraquat, detected in $29 \%$ and $28 \%$ of the positive pesticide analyses, respectively. Also relevant is the fact that quinalphos cases occurred mainly in men.

Other important pesticides such as parathion, dimethoate, and chlorfenvinphos were present, alone or associated with other pesticides, organophosphorus or organochlorines.

\section{Discussion}

Acute pesticide poisoning is recognized as a problem confined to the developing countries. Most estimates concerning the extent of acute pesticide poisoning have been based on data from hospital admissions, which would include only the more serious cases. The latest estimate by a WHO task group indicates that there may be one million serious unintentional poisonings each year and in addition two million people hospitalized for suicide attempts with pesticides [10].

A study performed in the Hospitals of the University of Coimbra (HUC), the most important central hospital of the district of Coimbra, based on a survey of poisoning admissions between January 1989 and December 2001, concluded

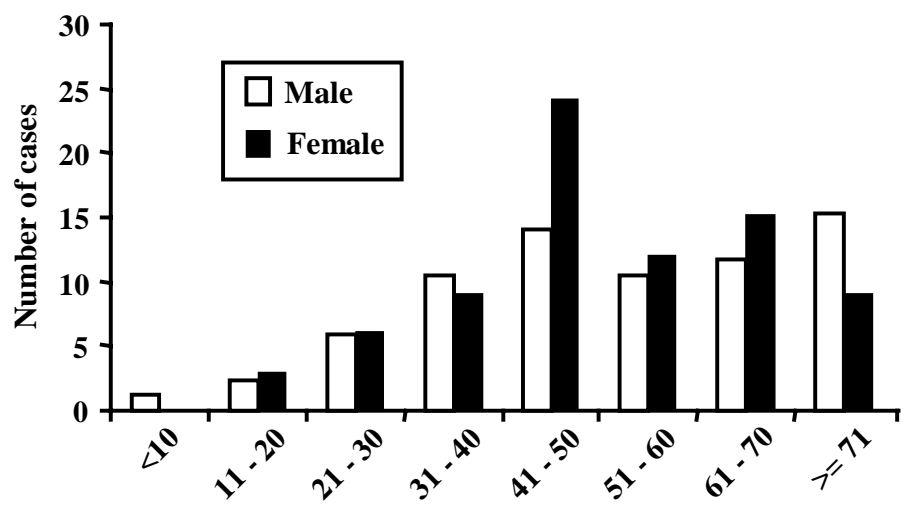

Age Groups

Fig. 2. Age and sex distribution of the total positive pesticide cases between January 2000 and December 2002. 
Table 2

Detected pesticides in forensic intoxications (clinical intoxications and deaths) between January 2000 and December 2002: analysis by year and sex

\begin{tabular}{|c|c|c|c|c|c|c|c|c|c|c|c|c|}
\hline \multirow[t]{3}{*}{ Detected pesticide } & \multicolumn{12}{|l|}{ Year } \\
\hline & \multicolumn{3}{|l|}{2000} & \multicolumn{3}{|l|}{2001} & \multicolumn{3}{|l|}{2002} & \multicolumn{3}{|l|}{ Total } \\
\hline & Total & Male & Female & Total & Male & Female & Total & Male & Female & Total & Male & Female \\
\hline Azinphos-ethyl & - & - & - & - & - & - & 1 & 1 & - & 1 & 1 & - \\
\hline Azinphos-methyl & - & - & - & 1 & 1 & - & - & - & - & 1 & 1 & - \\
\hline Cyfluthrin & - & - & - & - & - & - & 1 & 1 & - & 1 & 1 & - \\
\hline Chlorfenvinphos & - & - & - & 4 & 3 & 1 & 4 & 3 & 1 & 8 & 6 & 2 \\
\hline Chlorfenvinph. + Endosulfan & - & - & - & 1 & 1 & - & - & - & - & 1 & 1 & - \\
\hline Chlorpyrifos & - & - & - & - & - & - & 1 & - & 1 & 1 & - & 1 \\
\hline Deltamethrin & 1 & 1 & - & - & - & - & 1 & 1 & - & 2 & 2 & - \\
\hline Dimethoate & 2 & 1 & 1 & 8 & 6 & 2 & 1 & 1 & - & 11 & 7 & 3 \\
\hline Demeton-s-methyl-sulfon & - & - & - & - & - & - & 1 & 1 & - & 1 & 1 & - \\
\hline Fenthion & 1 & - & 1 & 1 & 1 & - & - & - & - & 2 & 1 & 1 \\
\hline Glyphosate & 2 & 2 & - & - & - & - & 1 & - & 1 & 3 & 2 & 1 \\
\hline Glyphosate + AMPA $^{\mathrm{a}}$ & 1 & 1 & - & - & - & - & 1 & 1 & - & 2 & 2 & - \\
\hline Oxydemeton-s-methyl & - & - & - & - & - & - & 1 & - & 1 & 1 & - & 1 \\
\hline Paraquat & 11 & 5 & 6 & 7 & 4 & 3 & 13 & 9 & 4 & 31 & 18 & 13 \\
\hline Parathion & 2 & 1 & 1 & 7 & 4 & 3 & 2 & 2 & - & 11 & 7 & 4 \\
\hline Parathion + Azinphos-ethyl & - & - & - & 1 & 1 & - & - & - & - & 1 & 1 & - \\
\hline Pendimethalin & - & - & - & - & - & - & 1 & - & 1 & 1 & - & 1 \\
\hline Quinalphos & 8 & 6 & 2 & 13 & 11 & 2 & 9 & 8 & 1 & 30 & 25 & 5 \\
\hline Quinalphos + Dichlorvos & 2 & 2 & - & - & - & - & - & - & - & 2 & 2 & - \\
\hline Total & 30 & 19 & 11 & 43 & 32 & 11 & 38 & 28 & 9 & 111 & 79 & 32 \\
\hline
\end{tabular}

${ }^{\mathrm{a}}$ AMPA, aminomethyl phosphonic acid.

that in a total of 1570 intoxication admissions, 132 cases resulted in deaths, of which $81 \%$ were due to pesticides [11]. These data support the considerably high number of pesticide requests made by hospitals to the Forensic Toxicology Laboratory (22\% of the total pesticides requests) (Fig. 1A).

The lack of studies and data published in Portugal about this subject makes a discussion of the results difficult [11]. Indeed, there are no published casuistic studies that deal reliably with the number and the characteristics of pesticide intoxications in Portugal, as well as their possible interpretation. In the present study there are, however, some aspects that may allow us to point out some trends, but with nothing else available to compare this to.

Our study emphasizes some general values, revealing an increase in the requests for pesticide toxicological analyses, showing the constant and current concern of all the health professionals about the non-controlled use of these products. The slight decrease of the positive results number, especially between 2001 and 2002, not corresponding to the evolution observed before (between 2000 and 2001) can only be explained after analyzing the next years pesticide intoxications, since it is not possible to offer any explanations or even conclude if this decreasing is going to be maintained or not.

An excessive use of pesticides in agriculture is still evident and, consequently, an overexposure of the subjects who handle seeders, especially males but also a small proportion of females who work in groundnut fields. This could justify the difference observed in forensic intoxications with these products between males (71.2\%) and females $(28.8 \%)$ (Table 1). Many of these subjects, not accustomed to handling pesticides, tend to overestimate the quantity of product to fill the seeders, possibly explaining why females were revealed to have higher non-intentional intoxications [11]. On the other hand, many subsistencefarming households have stocks of pesticides readily available for impulsive acts. Storage facilities and knowledge of pesticide toxicity are frequently poor. However, where toxicity is well recognized, paradoxical increases in the rate of poisoning also occur and many studies have shown that deliberate self-poisoning has a far higher mortality than accidental poisoning [12-14], and has a higher incidence in male individuals [11]. In Portugal, the studies performed by hospital admissions concluded that self-poisoning is definitely predominant, corresponding to $76.2 \%$ [11]. However, Parrón et al [15] stated that the incidence and circumstances of self-poisoning by pesticides are largely unknown due to lack of research, and were the first ones to investigate all suicides occurring in an intensive agricultural area with significant use of pesticides. They concluded that the most frequently used suicide method was poisoning with pesticides, accounting for $56.1 \%$ of the total, observing that the profession with the highest number of suicides was farmers, followed by housewives. They also noted that depression is often overlooked in farmers with occupational exposure to 
pesticides, as it may be masked by hypochondriasis or somatization, contributing to a greater risk of suicide in this group than in the general population. Other authors, from a study performed in England and Wales also found a high percentage $(73 \%)$ of pesticide-related deaths classified as suicides [16].

The most affected age group is the 40-50 year-olds (Fig. 2), reflecting individuals that are naturally still in an active working phase of their lives, and we also observe a high incidence of female positive cases in this age group, probably due to suicide or attempted suicide. Indeed, in Portugal, especially since 1977 , female suicide rates have risen in general and significantly among 20-49 year-olds [17]. Some other authors had concluded before that the age group of suicide risk was $40-49$, justified by growing old and the consequent lack of social integration (family reduced once their children leave home, retirement, widowhood) [18], which may explain our results.

It should be noted that the policy of distribution of pesticides in our country, which presents risks of poisoning, is usually accompanied by sufficient information on the danger of the products and of certain precautions that should be taken during their use. However, sometimes this is not accomplished or is misunderstood and accidents, voluntarily or not, occur. Therefore, as proposed by some authors [19], a minimum pesticide list should be drawn up in order to identify a restricted number of less dangerous pesticides for specific purposes within an integrated pest management system.

It is also important to be aware that, unfortunately, $66 \%$ of pesticide requests have no information about the putative cause of the incident, and so, efforts must be made in order to change this aspect. As known and reported by some authors [20], information in forensic toxicology plays a very important role because the forensic toxicologist usually performs toxicological analysis on the basis of the requests and crucially, the information available (suspected substances, liquids, or strange objects found near the body) at the time of the admission to hospitals and/or legal-medical autopsy, and it would obviously help to interpret the obtained results. Indeed, in another article made from a study performed in our institute, this problem was mentioned, the authors explaining that in toxicology it is very difficult to establish, with reliability, the medico-legal etiology, as this depends on the quality of information that is given to the medico-legal expert. In Portugal, the information that reaches the experts is, in some cases, unfortunately, very poor, only mentioning the simple statement 'pesticide ingestion', 'self-intended pesticide ingestion', or even 'pesticide intoxication' [21].

A previous study performed by this same Forensic Toxicology Laboratory, also concerning the intoxications in the Centre of Portugal [22], revealed that in the 1950s and 1960 s, arsenic was the toxic agent responsible for most of the forensic intoxications, followed by organophosphorous pesticides, detected for the first time in 1965. In the 1970s and 1980s, we witnessed a great increase in organophos- phorous pesticides in the forensic intoxications (108 cases between 1970 and 1979, and 562 cases between 1980 and 1989), azinphos-ethyl being the most important substance in the 1970s and parathion in the 1980s. In the 1990s, although we saw a decreasing number of cases due to organophosphorous pesticides (334), they still remain as the most important detected pesticides, but simultaneously new pesticide classes are also beginning to be responsible for forensic intoxications: the herbicides.

With respect to the three years (2000-2002) analyzed in this paper, we can see that organophosphorus insecticides still constitute the most important class of pesticides detected in forensic intoxications, representing $63 \%$ of the total positive cases, followed by herbicides, with $33 \%$ of the positive results (Table 2). In the study already mentioned, reporting intoxications in the HUC, the main pesticides encountered were organophosphorus pesticides and carbamates, followed by a smaller number of other pesticides [11], which seems to confirm our large number of cases of organophosphorus poisoning.

In the intoxications due to organophosphorus insecticides, quinalphos is the most important pesticide, present in 32 of the 111 positive cases ( 2 of them associated with another organophosphorous, dichlorvos), followed by parathion and dimethoate, and chlorfenvinphos (since 2001), detected in 9 cases, one associated with endosulfan (the only case with organochlorines). In fact, quinalphos was introduced in Portugal in 1986, and since then intoxications due to this product have started increasing, substituting the frequent intoxications by parathion and azinphos-ethyl [23]. Also relevant is that quinalphos cases occur mainly in men.

In $33 \%$ of the positive cases for herbicides, paraquat is the most important detected pesticide, present in almost the same number of cases as quinalphos. It is also relevant that in the positive cases for quinalphos there was never a previous indication of suicidal purpose in the analysis request form. On the other hand, in the 31 positive cases for paraquat, 10 had information of suicide and 7 with intoxication suspicion.

Thus, in these three last years, we are aware of a still high number of intoxications due to organophosphorous pesticides, but also an increase in the forensic cases with herbicides.

\section{Conclusion}

In the course of time and with progress in knowledge, after many years of a widespread use of pesticides, it is necessary to evaluate the negative results they cause. Poisonings with these xenobiotics still present a challenge and problems for toxicology.

This article emphasizes the need to control the problem on a collaborative basis by all concerned, including national governments, agrochemical industries, workers and scientists, and the adoption of an integrated pest management 
scheme, with a reduced use of agrochemicals and less longterm environmental damage, can only be beneficial and should be encouraged.

\section{References}

[1] S. Watanabee, Detection of organophosphate pesticides in blood serum from the patients suspected to acute and chronic pesticides poisonings and its clinical significance, Tohoku J. Exp. Med. 107 (1972) 301-302.

[2] M. Lifshitz, E. Shahak, A. Bolotin, S. Sofer, Carbamate and organophosphate poisoning in young children, Pediatr. Emerg. Care 15 (2) (1999) 102-103.

[3] D.E. Ray, Pesticide neurotoxicity in Europe: real risks and perceived risks, Neurotoxicology 21 (1-2) (2000) 219-221.

[4] E. Lacassie, P. Marquet, J.M. Gaulier, M.F. Dreyfuss, G. Lachâtre, Sensitive and specific multiresidue methods for the determination of pesticides of various classes in clinical and forensic toxicology, For. Sci. Int. 121 (2001) 116-125.

[5] R.S. Levine, J. Doull, Global estimates of acute pesticide morbidity and mortality, Rev. Environ. Contam. Toxicol. 129 (1992) 29-50.

[6] E.G.P. Marques, Acute intoxication by azinphos-ethyl, J. Anal. Toxicol. 14 (1990) 243-246.

[7] E.P. Marques, F. Gil, P. Proença, P. Monsanto, M.F. Oliveira, A. Castanheira, D.N. Vieira, Analytical method for the determination of strychnine in tissues by gas chromatography/mass spectrometry: two case reports, For. Sci. Int. 110 (2) (2000) 145-152.

[8] E. Lacassie, P. Marquet, J.-M. Gaulier, M.-F. Dreyfuss, G. Lachâtre, Sensitive and specific multiresidue methods for the determination of pesticides of various classes in clinical and forensic toxicology, For. Sci. Int. 121 (2001) 116-125.

[9] F. Guyon, C. Bismuth, J.P. Leclerc, F. Dauchy, Intoxication massive par le Paraquat mortelle en moins de $24 \mathrm{~h}$. Données toxicologiques et anatomocliniques, J. Eur. Toxicol. 7 (3) (1974) 182-187.

[10] J. Jeyratnam, Acute pesticide poisoning: a major global health problem, World Health Stat Q. 43 (3) (1990) 139-144.

[11] A.J.V. Queirós, Internamentos por Intoxicação nos Hospitais da Universidade de Coimbra: 1989-2001, Arquivos de Medicina 17 (4) (2003) 148-152.

[12] J. Hettiarachchi, G.C.S. Kodithuwakku, Pattern of poisoning in rural Sri Lanka, Int. J. Epidemiol. 18 (1989) 418-422.
[13] J. Ingianna, R. Herrero, C. Albertazzi, Estudio comparativo de casos de intoxicaciones por insecticides organofosforados en diferentes zones de Costa Rica, Rev. Biol. Trop. 31 (1983) 139-144.

[14] M. Abdollahi, N. Jalali, O. Sabzevari, R. Hoseini, T. Ghanea, A retospective study of poisoning in Tehran, Clin. Toxicol. 35 (1997) 387-393.

[15] T. Parrón, A.F. Hernández, E. Villanueva, Increased risk of suicide with exposure to pesticides in an intensive agricultural area. A 12-year retrospective study, For. Sci. Int. 79 (1996) 53-63.

[16] P. Casey, J.A. Vale, Deaths from pesticide poisoning in England and Wales: 1945-1989, Hum. and Exp. Toxicol. 13 (1994) 95-101.

[17] E.F. Castro, I. Martins, The role of female autonomy in suicide among Portuguese women, Acta Psychiatr. Scand. 75 (1987) 337-343.

[18] E. Freitas, O suicídio em Portugal no século XX, "O Médico" 102 (1590) (1982) 787-800.

[19] M. Eddleston, L. Karalliedde, N. Buckley, R. Fernando, G. Hutchinson, G. Isbister, F. Konradsen, D. Murray, J.C. Piola, N. Senanayake, R. Sheriff, S. Singh, S.B. Siwach, L. Smit, Pesticide poisoning in the developing world - a minimum pesticides list, Lancet 360 (9340) (2002) 1163-1167.

[20] L.L. Reys, J.C. Santos, Importance of information in forensic toxicology, Am. Forensic Med. Pathol. 13 (1) (1992) 33-36.

[21] F.O. Sá, J.A.P. Silva, D.N. Vieira, M.A. Rebelo, F.S. Costa, M.C. Cortesão, Intoxicações mortais. Casuística do Instituto de Medicina Legal de Coimbra nos últimos 45 anos (1943-1987), Segurança 24 (95) (1989) 35-41.

[22] E.G. Pinho Marques, H.M. Teixeira, P. Proença, M.M. Oliveira, A.M. Castanheira, M. Barroso, C. Margalho, S. Ávila, D.N. Vieira, Étude rétrospective, depuis les annés 50, des toxiques détectés dans des échantillons biologiques humains, de cadavres autopsiés dans les chefs-slieux appartenant à la corconscription médico-légale de Coimbra, Temas de Medicina Legal, Centro de Estudos de Pósgraduação em Medicina Legal, D.N. Vieira, A. Rebelo, C. Cordeiro Coord. (2002) 407-413.

[23] M.M. Oliveira, E.G. Pinho Marques, P.V. Monsanto, C. Margalho, A. Claro, E. Frias, F. Castanheira, D.N. Vieira, Intoxications par le pesticide organophosphoré chimalphos, Temas de Medicina Legal, Centro de Estudos de Pósgraduação em Medicina Legal, D.N. Vieira, A. Rebelo, C. Cordeiro Coord. (2002) 441-448. 